\title{
Clinical impact of multidrug-resistant bacteria in older hospitalized patients with community-acquired urinary tract infection
}

\author{
Manuel Madrazo', Ana Esparcia', Ian López-Cruz' , Juan Alberola ${ }^{2,3^{*}}$, Laura Piles', Alba Viana', \\ José María Eiros ${ }^{4}$ and Arturo Artero1,3
}

\begin{abstract}
Introduction: Previous studies have described some risk factors for multidrug-resistant (MDR) bacteria in urinary tract infection (UTI). However, the clinical impact of MDR bacteria on older hospitalized patients with communityacquired UTI has not been broadly analyzed. We conducted a study in older adults with community-acquired UTI in order to identify risk factors for MDR bacteria and to know their clinical impact.
\end{abstract}

Methods: Cohort prospective observational study of patients of 65 years or older, consecutively admitted to a university hospital, diagnosed with community-acquired UTI. We compared epidemiological and clinical variables and outcomes, from UTI due to MDR and non-MDR bacteria. Independent risk factors for MDR bacteria were analyzed using logistic regression.

Results: 348 patients were included, 41.4\% of them with UTI due to MDR bacteria. Median age was 81 years. Hospital mortality was $8.6 \%$, with no difference between the MDR and non-MDR bacteria groups. Median length of stay was 5 [4-8] days, with a longer stay in the MDR group (6 [4-8] vs. 5 [4-7] days, $p=0.029$ ). Inadequate empirical antimicrobial therapy (IEAT) was $23.3 \%$, with statistically significant differences between groups (33.3\% vs. 16.2\%, $p<0.001$ ). Healthcare-associated UTI variables, in particular previous antimicrobial therapy and residence in a nursing home, were found to be independent risk factors for MDR bacteria.

Conclusions: The clinical impact of MDR bacteria was moderate. MDR bacteria cases had higher IEAT and longer hospital stay, although mortality was not higher. Previous antimicrobial therapy and residence in a nursing home were independent risk factors for MDR bacteria.

Keywords: Older adults, Risk factor, Inadequate empirical antimicrobial therapy, Outcomes

\section{Introduction}

Antimicrobial resistance has become a major worldwide healthcare problem and especially infections caused by multidrug-resistant (MDR) microorganisms as they have a huge clinical and economic burden [1, 2]. Although

*Correspondence: Juan.alberola@uv.es

${ }^{2}$ Microbiology Department, Doctor Peset University Hospital, Avda. Gaspar Aguilar, n 90, 46017 Valencia, Spain

Full list of author information is available at the end of the article most of these infections are commonly associated with healthcare, MDR bacteria are also causing a growing number of community-acquired infections $[3,4]$.

Urinary tract infection (UTI) is among the most frequent causes of bacteremia and sepsis [5] and it is a very frequent cause of hospitalization due to infection in older adults [6]. Extended-spectrum beta-lactamases (ESBL) are enzymes produced by Escherichia coli and other bacteria that are common etiologies in UTI [7]. Simultaneous resistance to other antimicrobials is frequent 
since they are often encoded in the same plasmids that harbored the ESBL genes [8]. Therefore, MDR microorganisms are an increasing cause of UTI in both community-acquired and healthcare-associated infections [9-11] which could lead to a higher rate of treatment failure [12].

Previous studies have described some risk factors for MDR bacteria in UTI [13-15]. However, most of these studies are retrospective and include both nosocomial and community-acquired UTI. The clinical impact of MDR bacteria on older hospitalized patients with community-acquired UTI has not been broadly analyzed [16]. Therefore, we conducted a prospective study in older adults with community-acquired UTI admitted to hospital in order to identify risk factors for MDR bacteria and to know their clinical impact.

\section{Material and methods}

Cohort prospective observational study of patients of 65 years or older consecutively admitted to an internal medicine ward at a university hospital diagnosed with community acquired UTI, from January 2016 to December 2019. Cases with a negative urine culture or a clinical syndrome compatible with any other condition after reviewing the case were excluded, as well as nosocomial or UTI cases transferred from the Intensive Care Unit (ICU). Epidemiological and clinical variables were collected by the authors following a protocol. All the cases were reviewed by two independent researchers (MM and $\mathrm{AE})$ before being included in the study.

Multidrug-resistance (MDR) was defined according to an international expert proposal by Magiorakos et al. [17], as non-susceptibility to at least one agent in three or more antimicrobial categories (extended-spectrum penicillins, carbapenems, cephalosporins, aminoglycosides, and fluoroquinolones for gramnegative bacteria; and ampicillin, vancomycin, fluoroquinolones, fosfomycin and linezolid for grampositive bacteria). Extensively drug-resistance (XDR) was defined as non-susceptibility to at least one agent in all but two or fewer antimicrobial categories tested for a particular microorganism. SOFA and qSOFA scales were used according to their original definitions [18] and measured within 24 h of admission at the Emergency Department (ED). Community onset healthcare-associated UTI (HCA-UTI) was defined as a community onset UTI with any of the following criteria: (i) to have been admitted to an acute care hospital $\geq 48 \mathrm{~h}$ within 90 days previous to current hospital admission; (ii) to have received antimicrobial therapy within 90 days previous to admission; and (iii) residing in a nursing home [19]. IEAT was considered as the occurrence of infection that was not effectively treated at the time when the causative microorganism and its antimicrobial susceptibility were known. This included the absence of antimicrobial agents directed at a specific class of microorganisms and the administration of an antimicrobial agent to which the microorganism responsible for the infection was resistant [19].

Quantitative variables were compared using Student's t-test or analysis of variance (ANOVA) when the distribution was normal, or Mann-Whitney U-test when it was not normal. Qualitative variables were compared with chi square test and Fisher's exact test. Multivariate analysis was performed using logistic regression, considering an $\alpha$ significance level of 0.05 for all tests. All tests were two sided. If any data was missing, a normal value was attributed for the calculation. The statistical package SPSS version 22 from IBM for Windows was used for the statistical analysis.

\section{Results}

Out of 1258 patients diagnosed with community acquired UTI admitted to hospital during the period of study, 348 patients were included (Fig. 1). MDR bacteria caused $41.4 \%$ of the cases, including $7.8 \%$ cases with XDR bacteria. Mean age was 81 years, and $51.4 \%$ were male. Diabetes mellitus (37.4\%), chronic kidney disease (32.5\%) and dementia (29.9\%) were the most frequent comorbidities. $52.9 \%$ of the patients were septic and $16 \%$ had septic shock on admission. Other epidemiological and clinical characteristics and outcomes may be seen in Table 1.

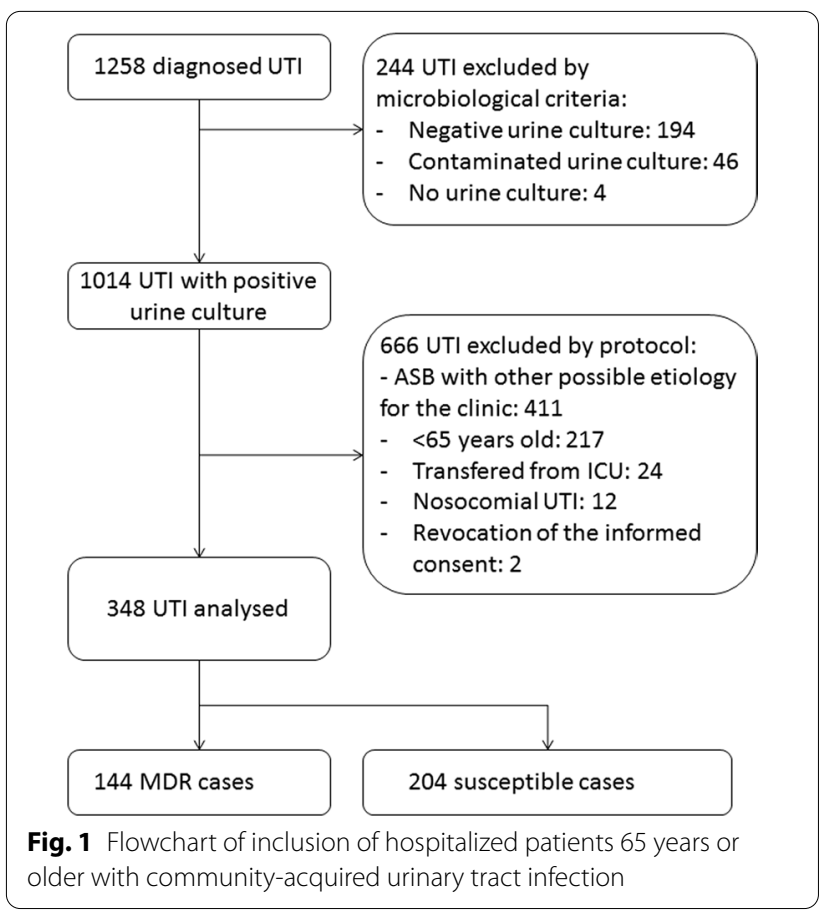


Table 1 Epidemiological and clinical characteristics and outcomes of community-acquired urinary tract infection in older patients according to multidrug-resistant or non-multidrug-resistant bacteria

\begin{tabular}{|c|c|c|c|c|}
\hline & $\begin{array}{l}\text { Total cases } \\
\text { n } 348\end{array}$ & $\begin{array}{l}\text { MDR bacteria } \\
\text { n } 144\end{array}$ & $\begin{array}{l}\text { Non-MDR bacteria } \\
\text { n } 204\end{array}$ & $p$ \\
\hline Male sex, n (\%) & $179(51.4)$ & $82(56.9)$ & $97(47.5)$ & 0.102 \\
\hline Age (years), median [IQR] & $81[75-87]$ & $80[75-88]$ & $81[75-87]$ & 0.719 \\
\hline Age $\geq 75$ years, $n(\%)$ & $274(78.7)$ & $111(77.1)$ & $163(79.9)$ & 0.595 \\
\hline McCabe $\geq 2, n(\%)$ & $268(77)$ & $113(78.5)$ & $155(75.9)$ & 0.607 \\
\hline \multicolumn{5}{|l|}{ Comorbidites } \\
\hline Dementia, n (\%) & $104(29.9)$ & $52(36.1)$ & $52(25.5)$ & 0.043 \\
\hline Diabetes mellitus, n (\%) & $130(37.4)$ & $56(38.9)$ & $74(36.3)$ & 0.653 \\
\hline COPD, n (\%) & $51(14.7)$ & $20(13.9)$ & $31(15.2)$ & 0.761 \\
\hline CKD, n (\%) & $113(32.5)$ & $44(30.6)$ & $69(33.8)$ & 0.562 \\
\hline Cancer, n (\%) & $77(22.1)$ & $30(20.8)$ & $47(23)$ & 0.695 \\
\hline Indwelling urinary catheter, n (\%) & $81(23.3)$ & $40(27.8)$ & $41(20.1)$ & 0.122 \\
\hline HCA-UTI, n (\%) & $214(61.5)$ & $110(76.4)$ & $104(50.9)$ & $<0.001$ \\
\hline Previous hospitalization, n (\%) & $128(36.8)$ & $67(46.5)$ & $61(29.9)$ & 0.002 \\
\hline Previous antimicrobial therapy, n (\%) & $182(52.3)$ & $94(65.3)$ & $88(43.1)$ & $<0.001$ \\
\hline Nursing home residence, $\mathrm{n}(\%)$ & $28(8)$ & $20(13.9)$ & $8(3.9)$ & 0.001 \\
\hline \multicolumn{5}{|l|}{ Clinical characteristics } \\
\hline APACHE II, median [IQR] & $12[9-17]$ & $13[9-17]$ & $12[9-17]$ & 0.981 \\
\hline Fever, n (\%) & $239(68.7)$ & $98(68.1)$ & $141(69.1)$ & 0.907 \\
\hline$R R \geq 22, n(\%)$ & $71(20.4)$ & $23(15.9)$ & $48(23.5)$ & 0.105 \\
\hline Altered mental status, n (\%) & $158(45.4)$ & $76(52.8)$ & $82(40.2)$ & 0.021 \\
\hline $\mathrm{SBP}<100, \mathrm{n}(\%)$ & $62(17.8)$ & $30(20.8)$ & $32(15.7)$ & 0.255 \\
\hline qSOFA $\geq 2, n(\%)$ & $90(25.9)$ & $40(27.8)$ & $50(24.5)$ & 0.535 \\
\hline Sepsis (SOFA $\geq 2$ ), n (\%) & $184(52.9)$ & $78(54.1)$ & $106(51.9)$ & 0.744 \\
\hline Septic shock-3, n (\%) & $56(16)$ & $25(17.4)$ & $31(15.2)$ & 0.657 \\
\hline Albumin, median [IQR] & $3.1[2.8-3.5]$ & $3.0[2.7-3.5]$ & $3.2[2.9-3.5]$ & 0.063 \\
\hline Leukocytosis, median [IQR] & $13,200[9400-18575]$ & $12,800[9025-18425]$ & 13,500 [9750-18600] & 0.170 \\
\hline Polymicrobial UTI, n (\%) & $36(10.3)$ & $21(14.6)$ & $15(7.4)$ & 0.033 \\
\hline Bacteremia, positive/total blood cultures (\%) & $84 / 209(40.2)$ & $35 / 85(41.2)$ & 49/124 (39.5) & 0.951 \\
\hline IEAT, n (\%) & $81(23.3)$ & $48(33.3)$ & $33(16.2)$ & $<0.001$ \\
\hline \multicolumn{5}{|l|}{ Outcomes } \\
\hline In-hospital mortality, n (\%) & $30(8.6)$ & $11(7.6)$ & $19(9.3)$ & 0.699 \\
\hline 30-day mortality, n (\%) & $44(12.6)$ & $20(13.9)$ & $24(11.8)$ & 0.624 \\
\hline Length of hospital stay (days), median [IQR] & $5[4-8]$ & $6[4-8]$ & $5[4-7]$ & 0.029 \\
\hline
\end{tabular}

MDR, multidrug-resistant; COPD, chronic obstructive pulmonary disease; CKD, chronic kidney disease; HCA-UTI, healthcare associated-UTI; RR, respiratory rate; SBP, systolic blood pressure; IEAT, inadequate empiric antimicrobial therapy

Hospital mortality was $8.6 \%$ and 30 -day mortality was $12.6 \%$, with no difference between the MDR and nonMDR groups. Mean length of stay was 5 [4-8] days, with a longer stay in the MDR bacteria group. IEAT was $23.3 \%$, with statistically significant differences between groups $(33.3 \%$ vs. $16.2 \%, \mathrm{p}<0.001)$.

MDR was associated with dementia, healthcare-associated UTI (including previous use of antimicrobials, previous admission at hospital and residing in a nursing home), and altered mental status at admission in the univariate analysis (Table 1). Healthcare-associated UTI variables, in particular previous antimicrobial therapy and residence in a nursing home, were found to be independent risk factors for MDR bacteria by multivariate analysis, but previous hospitalization was not (Table 2).

Escherichia coli was the most frequent microorganism (56.4\%), followed by Klebsiella pneumoniae (13.4\%) and Enterococcus faecalis (8.5\%), as shown in Table 3. The most frequent MDR bacteria were E. coli, K. pneumoniae and Enterobacter cloacae (60.5\%, 12.6\% and $6.7 \%$ of the total cases, respectively). There were no cases of panresistant bacteria. Multidrug-resistance in 
Table 2 Multivariate analysis by logistic regression of risk factors for multidrug-resistant bacteria producing urinary tract infection in older patients

\begin{tabular}{lcccc}
\hline & Univariate analysis $\mathbf{p}$ & OR (IC 95\%) & Multivariate analysis $\mathbf{p}$ & OR (IC 95\%) \\
\hline Dementia & 0.043 & $1.6(1.1-1.7)$ & 0.255 & - \\
Altered mental status & 0.021 & $1.4(1.1-1.8)$ & 0.197 & - \\
Previous hospitalization & 0.002 & $1.5(1.2-1.9)$ & 0.433 & - \\
Previous antimicrobial therapy & $<0.001$ & $1.7(1.3-2.5)$ & 0.003 & $1.7(0.6-2.9)$ \\
Residence in a nursing home & 0.001 & $1.8(1.4-2.4)$ & 0.005 & $2.7(0.8-4.6)$ \\
\hline
\end{tabular}

Table 3 Etiology of 348 cases of community-acquired urinary tract infection in older hospitalized patients according to multidrug-resistant and non-multidrug-resistant bacteria

\begin{tabular}{|c|c|c|c|}
\hline & $\begin{array}{l}\text { Total } \\
\text { n } 388\end{array}$ & $\begin{array}{l}\text { MDR bacteria } \\
\text { n } 147\end{array}$ & $\begin{array}{l}\text { Non-MDR bacteria } \\
\text { n } 241\end{array}$ \\
\hline \multicolumn{4}{|c|}{ Gramnegative bacteria, n (\%) } \\
\hline Escherichia coli & $219(56.4)$ & $86(39.26)$ & $133(60.73)$ \\
\hline $\begin{array}{l}\text { Klebsiella pneumo- } \\
\text { niae }\end{array}$ & $52(13.4)$ & $20(38.46)$ & $32(61.54)$ \\
\hline $\begin{array}{l}\text { Pseudomonas } \\
\text { aeruginosa }\end{array}$ & $28(7.2)$ & $7(25)$ & $21(75)$ \\
\hline Klebsiella oxytoca & $11(2.8)$ & $3(27.27)$ & $8(72.72)$ \\
\hline $\begin{array}{l}\text { Enterobacter } \\
\text { cloacae }\end{array}$ & $10(2.6)$ & $10(100)$ & 0 \\
\hline Proteus mirabilis & $9(2.3)$ & $6(66.67)$ & $3(33.33)$ \\
\hline $\begin{array}{l}\text { Other Enterobacte- } \\
\text { riaceae }\end{array}$ & $12(3.1)$ & $8(66.67)$ & $4(33.33)$ \\
\hline \multicolumn{4}{|c|}{ Grampositive bacteria, n (\%) } \\
\hline $\begin{array}{l}\text { Enterococcus } \\
\text { faecalis }\end{array}$ & $33(8.5)$ & $2(6.06)$ & $31(93.94)$ \\
\hline $\begin{array}{l}\text { Enterococcus } \\
\text { faecium }\end{array}$ & $5(1.3)$ & $1(20)$ & $4(80)$ \\
\hline $\begin{array}{l}\text { Acinetobacter } \\
\text { baumanii }\end{array}$ & $3(0.8)$ & $3(100)$ & 0 \\
\hline $\begin{array}{l}\text { Enterococcus gal- } \\
\text { linarum }\end{array}$ & $2(0.5)$ & $1(50)$ & $1(50)$ \\
\hline $\begin{array}{l}\text { Streptococcus } \\
\text { agalactiae }\end{array}$ & $1(0.3)$ & 0 & $1(100)$ \\
\hline \multicolumn{4}{|l|}{ Fungi, n (\%) } \\
\hline Candida spp. & $3(0.8)$ & 0 & $3(100)$ \\
\hline
\end{tabular}

$\mathrm{MDR}$, multidrug-resistant

E. faecalis was low (6\%), with just one case of resistance to Ampicillin and none to Vancomycin.

Ampicillin showed the highest rate of resistance (75.6\%), followed by ciprofloxacin (42.8\%) and trimethoprim/sulfamethoxazole (40.5\%). Resistance rates for Imipenem, Piperacillin/Tazobactam and Fosfomycin were low (4\%, $6.4 \%$ and $15.6 \%$, respectively), as well as resistance rate for Vancomycin among grampositive bacteria $(4.3 \%)$.

\section{Discussion}

Our findings in this study indicate that the clinical impact of MDR bacteria in older patients with community-acquired UTI was moderate. There was no difference in mortality and, despite IEAT being twice the percentage in the MDR bacteria group, the length of hospital stay was just 1 day longer.

In our study, MDR bacteria accounted for $41.4 \%$ of the cases of community-acquired UTI in hospitalized patients older than 65 years. This percentage is comparable to other results described in a similar setting (35.2\% to $46.1 \%$ ) [20-22], and higher than those of other studies on UTI outpatients (1.6\% to $1.9 \%)[11,23]$ or in the ED (6.7\%) [24].

MDR cases were associated with IEAT (33.3\% vs. $16.2 \%, \mathrm{p}<0.001)$ and a longer hospital stay $(6[4-8]$ vs. 5 [4-7] days, $p=0.029$ ). Lee et al. [25], comparing MDR and non-MDR Enterobacteriaceae causing bacteraemic UTI, described similarly an effectiveness of empirical therapy of $43.5 \%$ vs. $93.9 \%, \mathrm{p}<0.001$, and an increase in hospital stay $(11.2 \pm 6-62$ vs. $9.27 \pm 5.09$ days, $\mathrm{p}<0.001)$. In the same way, Tumbarello et al. [26] described an IEAT of $53.8 \%$ vs. $23.3 \%$ in a study with MDR and non-MDR P. aeruginosa UTI, as well as a longer hospital stay ( 48 vs. 22 days, $\mathrm{p}<0.001$ ).

In our study, in-hospital mortality was $8.6 \%$ and 30 -day mortality was $12.6 \%$, both higher than that found in other studies $(2.2 \%$ to $3.3 \%$ and 6 to $9.4 \%$, respectively) [20, 27-29], in which the mean age of the patients was lower. Nevertheless, our findings were lower than that found by Karve et al. (15\% and 18.6\%) [22]. MDR bacteria were not associated with mortality, neither in-hospital mortality nor 30-day mortality, similarly to that found in other studies with younger adults patients $[25,26]$. Studies on the effects of antibiotic resistance on fitness often document fitness costs of varying severity [30], and this could explain the no difference in mortality between resistant and nonresistant infections in our study, although there was a difference in appropriate and inappropriate antibiotic treatment. 
We would point out that in our study age and male sex were not associated with MDR bacteria, contrary to other studies on UTI, which included adult patients but not exclusively patients aged 65 or over [14, 16, 21]. It is a misconception that merely by being older, patients have more MDR infections. But this is not the case, as our findings suggest and in addition it can be seen in the works of Tumbarello et al. [26] and Faine et al. [24]. Comorbidities have been related to resistance in some studies $[14,25,26]$, contrary to our results. In our study, only dementia and altered mental status on admission were significantly related to MDR in the univariate analysis, but not in the multivariate analysis, as in other studies with younger patients $[16,26]$.

Previous case history for healthcare related infection, in particular previous antimicrobial therapy or residence in a nursing home, was associated with MDR bacteria in our study. Previous antimicrobial therapy is one of the most important variables regarding multiresistance [14, $16,21,31]$ along with residing in a nursing home $[14,16$, $21,24,31,32]$. Previous hospitalization has been related to resistance in some studies [14, 21,31], but it was not significant in the multivariate analysis in our study, as well as in other works [16, 24, 32], The use of indwelling catheter has been traditionally related to the development of resistance $[21,26]$, but this was not the case in our results, as in other studies [16, 32].

ESBL-producing Enterobacteriaceae had a prevalence of $12.1 \%$ in our study, lower than the prevalence for ESBL-producing Enterobacteriaceae described in hospitalized patients in Europe (20\%) [9] and North America (16.9\%) [33], in studies with both community-acquired and nosocomial UTI. Our prevalence was similar to the 13.4\% described by Smithson et al. [16] in older patients in the ED.

The resistance to ciprofloxacin was $42.8 \%$, similar to other studies (46.8\% to $47.7 \%$ ) [34, 35], which warrants not using ciprofloxacin as empirical antimicrobial therapy [34, 36]. Fosfomycin is an antimicrobial drug used mainly in primary care, where low resistance rate is described [11]. However, in recent years, it has also been recommended for patients with MDR bacteria such as ESBL producing Enterobacteriaceae [4, 37], especially in older patients [7]. The low resistance rate in our case (15.6\%) corroborates its usefulness as empirical treatment.

The main pathogens found in the urine culture, as expected, were E. coli, K. pneumoniae and E. faecalis. $E$. coli and K. pneumoniae were also the most frequent MDR bacteria $(39.26 \%$ and $38.46 \%$ of the respective cases), similar to other studies describing gramnegative bacteria UTI [13] and Enterobacteriaceae-UTI [25]. There were only two cases of MDR E. faecalis, both in patients older than 85 years with healthcare associated infection, as described in other study [38], and none of them was resistant to vancomycin.

The main strength of our study is that it was conceived from a clinical point of view, embracing all the UTI in the population of our interest, and avoiding possible confounders had the study stemmed from the results of the urine cultures. It is not centered on a group of resistant microorganism such as Enterobacteriaceae [27], Pseudomonas aeruginosa [26] or gramnegative bacteria [9]; and it does not select only one type of the clinical spectrum of UTI, such as bacteremic UTI $[1,25]$. We think that this patient orientated approach and overall view may help the clinician to treat better older patients with community-acquired UTI. Other strengths are the prospective design, as well as its rigorous selection of cases, conducted in every case by two independent researchers. The main limitation of this work is that it was carried out in a single center, with the bias that it represents, especially regarding etiology and resistance rates. Population in our study corresponds to older patients admitted to an internal medicine department. Indeed, it is a strength because this population is not always well represented in other studies [16], but it is also a limitation, as our findings could differ in other populations with UTI, such as patients attended in the ED or admitted to the ICU and those with nosocomial UTI. Another limitation is that we did not collect the antecedent of UTI caused by a MDR bacteria, which has been proved to be an important risk factor for antimicrobial resistance [34, 39, 40]. All in all, we believe that our findings add knowledge on risk factors for community-acquired UTI caused by MDR-bacteria and on their clinical impact in older adults, which can lead to better management of UTI in this population.

\section{Conclusion}

In this prospective study in older patients with community-acquired UTI, the clinical impact of MDR bacteria was moderate. Cases caused by MDR bacteria had higher IEAT and longer hospital stay, although no higher mortality. MDR bacteria caused almost half of the cases of community-acquired UTI in our series, previous antimicrobial therapy and residence in a nursing home being independent risk factors.

\section{Acknowledgements}

Not applicable.

\section{Authors' contributions}

MM methodology, validation. AE methodology, Validation. ILC methodology, validation. JA supervision, writing-review \& editing. LP methodology, validation. AV methodology, validation. JME methodology, validation. AA conceptualization, formal analysis, validation, original draft preparation. All authors read and approved the final manuscript. 


\section{Funding}

This research did not receive any specific grant from funding agencies in the public, commercial, or not-for-profit sectors.

\section{Availability of data and materials}

The datasets used and/or analysed during the current study are available from the corresponding author on reasonable request.

\section{Declarations}

\section{Ethics approval and consent to participate}

The study was approved by the Clinical Research Ethics Committee of the Doctor Peset University Hospital. Treatment of data, information sheet and informed consent are in accordance under the provisions of the Declaration of Helsinki (version of Fortaleza 2013). Informed consent was signed by every patient or his legal representative when the patient was unable to consent.

\section{Consent for publication}

Informed consent was signed by every patient or his legal representative when the patient was unable to consent.

\section{Competing interests}

The authors have no competing interests as defined by BMC, or other interests that might be perceived to influence the results and/or discussion reported in this paper.

\section{Author details}

${ }^{1}$ Internal Medicine Department, Doctor Peset University Hospital, Avda. Gaspar Aguilar, n 90, 46017 Valencia, Spain. ${ }^{2}$ Microbiology Department, Doctor Peset University Hospital, Avda. Gaspar Aguilar, n 90, 46017 Valencia, Spain. ${ }^{3}$ Universitat de València, Avda. Blasco Ibañez, n 17, 46010 Valencia, Spain. ${ }^{4}$ Department of Microbiology and Parasitology, Rio Hortega University Hospital, University of Valladolid, C/ Dulzaina, 2, 47012 Valladolid, Spain.

Received: 24 October 2021 Accepted: 30 November 2021 Published online: 07 December 2021

\section{References}

1. Kadri SS, Lai YL, Warner S, Strich JR, Babiker A, Ricotta EE, et al. Inappropriate empirical antibiotic therapy for bloodstream infections based on discordant in-vitro susceptibilities: a retrospective cohort analysis of prevalence, predictors, and mortality risk in US hospitals. Lancet Infect Dis. 2021;21(2):241-51.

2. Tabak YP, Sung AH, Ye G, Vankeepuram L, Gupta V, McCann E. Attributable clinical and economic burden of carbapenem-non-susceptible Gramnegative infections in patients hospitalized with complicated urinary tract infections. J Hosp Infect. 2019;102(1):37-44.

3. Jernigan JA, Hatfield KM, Wolford H, Nelson RE, Olubajo B, Reddy SC, et al. Multidrug-resistant bacterial infections in U.S. hospitalized patients, 2012-2017. N Engl J Med. 2020;382(14):1309-19.

4. Bader MS, Loeb M, Brooks AA. An update on the management of urinary tract infections in the era of antimicrobial resistance. Postgrad Med. 2017;129(2):242-58

5. Rudd KE, Johnson SC, Agesa KM, Shackelford KA, Tsoi D, Kievlan DR, et al. Global, regional, and national sepsis incidence and mortality, 1990-2017: analysis for the Global Burden of Disease Study. Lancet. 2020;395(10219):200-11.

6. Nicolle LE. Urinary tract infections in the older adult. Clin Geriatr Med. 2016;32(3):523-38.

7. Clifford K, Grelle J, Tawwater J, Ramanathan M, Duncan N. Management of ESBL urinary tract infections: diagnostic and treatment considerations for the Older Adult. Sr Care Pharm. 2019;34:645-59.

8. Rodriguez-Bano J, Gutiérrez-Gutiérrez B, Machuca I, Pascual A. Treatment of infections caused by ESBL, AmpC and Carbapenemase-producing Enterobacteriaceae. Clin Microbiol Rev. 2018;31(2):e00079-e117.

9. Mazzariol A, Bazaj A, Cornaglia G. Multi-drug-resistant Gram-negative bacteria causing urinary tract infections: a review. J Chemother. 2017;29(sup1):2-9.
10. Rosello A, Hayward AC, Hopkins S, Horner C, Ironmonger D, Hawkey PM, et al. Impact of long-term care facility residence on the antibiotic resistance of urinary tract Escherichia coli and Klebsiella. J Antimicrob Chemother. 2017;72(4):1184-92.

11. Rossignol L, Vaux S, Maugat S, Blake A, Barlier R, Heym B, et al. Incidence of urinary tract infections and antibiotic resistance in the outpatient setting: a cross-sectional study. Infection. 2017;45(1):33-40.

12. Naziri Z, Derakhshandeh A, Soltani Borchaloee A, Poormaleknia M, Azimzadeh N. Treatment failure in urinary tract infections: a warning witness for virulent multi-drug resistant ESBL- producing Escherichia coli. Infect Drug Resist. 2020;13:1839-50.

13. Gomila A, Shaw E, Carratala J, Leibovici L, Tebe C, Wiegand I, et al. Predictive factors for multidrug-resistant gram-negative bacteria among hospitalised patients with complicated urinary tract infections. Antimicrob Resist Infect Control. 2018;7:111.

14. Malcolm W, Fletcher E, Kavanagh K, Deshpande A, Wiuff C, Marwick C, et al. Risk factors for resistance and MDR in community urine isolates: population-level analysis using the NHS Scotland Infection Intelligence Platform. J Antimicrob Chemother. 2018;73(1):223-30.

15. Hitzenbichler F, Simon M, Holzmann T, Iberer M, Zimmermann M, Salzberger B, et al. Antibiotic resistance in E. coli isolates from patients with urinary tract infections presenting to the emergency department. Infection. 2018;46(3):325-31.

16. Smithson A, Ramos J, Nino E, Culla A, Pertierra U, Friscia M, et al. Characteristics of febrile urinary tract infections in older male adults. BMC Geriatr. 2019;19(1):334.

17. Magiorakos A, Srinivasan A, Carey R, Carmeli Y, Falagas M, Giske C, et al. Multidrug-resistant, extensively drut-resistant and pandrug-resistant bacteria: an international expert proposal for interim standard definitions for acquired resistance. Clin Microbiol Infect. 2012;18:268-81.

18. Seymour CW, Liu VX, Iwashyna TJ, Brunkhorst FM, Rea TD, Scherag A, et al. Assessment of clinical criteria for sepsis: for the third international consensus definitions for sepsis and septic shock (Sepsis-3). JAMA. 2016;315(8):762-74

19. Esparcia A, Artero A, Eiros JM, Balaguer M, Madrazo M, Alberola J, et al. Influence of inadequate antimicrobial therapy on prognosis in elderly patients with severe urinary tract infections. Eur J Int Med. 2014;25:523-7.

20. Gomila A, Carratala J, Eliakim-Raz N, Shaw E, Tebe C, Wolkewitz M, et al. Clinical outcomes of hospitalised patients with catheter-associated urinary tract infection in countries with a high rate of multidrug-resistance: the Combacte-Magnet Rescuing study. Antimicrob Resist Infect Control. 2019:8:198

21. Bischoff S, Walter T, Gerigk M, Ebert M, Vogelmann R. Empiric antibiotic therapy in urinary tract infection in patients with risk factors for antibiotic resistance in a German emergency department. BMC Infect Dis. 2018;18(1):56.

22. Karve S, Ryan K, Peeters P, Baelen E, Rojas-Farreras S, Potter D, et al. The impact of initial antibiotic treatment failure: real-world insights in patients with complicated urinary tract infection. J Infect. 2018;76(2):121-31.

23. Fasugba O, Das A, Mnatzaganian G, Mitchell BG, Collignon P, Gardner A. Incidence of single-drug resistant, multidrug-resistant and extensively drug-resistant Escherichia coli urinary tract infections: an Australian laboratory-based retrospective study. J Glob Antimicrob Resist. 2019;16:254-9.

24. Faine BA, Harland KK, Porter B, Liang SY, Mohr N. A clinical decision rule identifies risk factors associated with antimicrobial-resistant urinary pathogens in the emergency department: a retrospective validation study. Ann Pharmacother. 2015;49(6):649-55.

25. Lee YC, Hsiao CY, Hung MC, Hung SC, Wang HP, Huang YJ, et al. Bacteremic urinary tract infection caused by multidrug-resistant Enterobacteriaceae are associated with severe sepsis at admission: implication for empirical therapy. Medicine (Baltimore). 2016;95(20):e3694.

26. Tumbarello M, Raffaelli F, Peghin M, Losito AR, Chirico L, Giuliano G, et al. Characterisation and risk factor profiling of Pseudomonas aeruginosa urinary tract infections: pinpointing those likely to be caused by multidrugresistant strains. Int J Antimicrob Agents. 2020;55(4):105900.

27. Lee H, Baik S, Ji H, Kim H, Kang S, Durey A. Risk factors of urinary tract infection caused by extended spectrum B-lactamase-producing Escherichia coli in emergency department. Am J Emerg Med. 2018;36(9):1608-12. 
28. Mitchell BG, Ferguson JK, Anderson M, Sear J, Barnett A. Length of stay and mortality associated with healthcare-associated urinary tract infections: a multi-state model. J Hosp Infect. 2016;93(1):92-9.

29. Gomez Belda AB, De la Fuente J, Diez LF, Capdevila JA, Inglada L, Arca $A$, et al. Inadequate empirical antimicrobial treatment in older people with bacteremic urinary tract infection who reside in nursing homes: a multicenter prospective observational study. Geriatr Gerontol Int. 2019;19(11):1112-7.

30. Andersson DI, Hughes D. Antibiotic resistance and its cost: is it possible to reverse resistance? Nat Rev Microbiol. 2010;8(4):260-71.

31. Tenney J, Hudson N, Alnifaidy H, Li JTC, Fung KH. Risk factors for aquiring multidrug-resistant organisms in urinary tract infections: a systematic literature review. Saudi Pharm J. 2018;26(5):678-84.

32. Faine BA, Mohr N, Vakkalanka P, Gao AS, Liang SY. Validation of a clinical decision rule to identify risk factors associated with multidrug-resistant urinary pathogens in the emergency department. Ann Pharmacother. 2019;53(1):56-60.

33. Talan DA, Takhar SS, Krishnadasan A, Mower WR, Pallin DJ, Garg M, et al. Emergence of extended-spectrum beta-lactamase urinary tract infections among hospitalized emergency department patients in the United States. Ann Emerg Med. 2021;77(1):32-43.

34. Dickstein Y, Geffen Y, Andreassen S, Leibovici L, Paul M. Predicting antibiotic resistance in urinary tract infection patients with prior urine cultures. Antimicrob Agents Chemother. 2016;60(8):4717-21.

35. Ramirez-Castillo FY, Moreno-Flores AC, Avelar-Gonzalez FJ, MarquezDiaz F, Harel J, Guerrero-Barrera AL. An evaluation of multidrug-resistant Escherichia coli isolates in urinary tract infections from Aguascalientes, Mexico: cross-sectional study. Ann Clin Microbiol Antimicrob. 2018;17(1):34

36. Korkmaz P, Kurtaran B, Özdemir Armağan Ş, Turan Özden H, Kacar F, Ateş $\mathrm{S}$, et al. The factors affecting inadequate empirical antimicrobial therapy and clinical course in upper urinary tract infections of the elderly patients. Mediterr J Infect Microb Antimicrob. 2020. https://doi.org/10.4274/mjima. galenos.2020.2020.5.

37. Babiker A, Clarke L, Doi Y, Shields RK. Fosfomycin for treatment of multidrug-resistant pathogens causing urinary tract infection: a realworld perspective and review of the literature. Diagn Microbiol Infect Dis. 2019;95(3):114856.

38. Farman M, Yasir M, Al-Hindi RR, Farraj SA, Jiman-Fatani AA, Alawi M, et al. Genomic analysis of multidrug-resistant clinical Enterococcus faecalis isolates for antimicrobial resistance genes and virulence factors from the western region of Saudi Arabia. Antimicrob Resist Infect Control. 2019;8:55.

39. Ahn ST, Kim SW, Kim JW, Park HS, Moon DG, Oh MM. Does urinary tract infection caused by extended-spectrum beta-lactamase-producing Escherichia coli show same antibiotic resistance when it recurs? J Infect Chemother. 2019;25(7):498-502.

40. Anesi JA, Lautenbach E, Nachamkin I, Garrigan C, Bilker WB, Omorogbe $J$, et al. The role of extended-spectrum cephalosporin-resistance in recurrent community-onset Enterobacteriaceae urinary tract infections: a retrospective cohort study. BMC Infect Dis. 2019;19(1):163.

\section{Publisher's Note}

Springer Nature remains neutral with regard to jurisdictional claims in published maps and institutional affiliations.

Ready to submit your research? Choose BMC and benefit from:

- fast, convenient online submission

- thorough peer review by experienced researchers in your field

- rapid publication on acceptance

- support for research data, including large and complex data types

- gold Open Access which fosters wider collaboration and increased citations

- maximum visibility for your research: over $100 \mathrm{M}$ website views per year

At $\mathrm{BMC}$, research is always in progress.

Learn more biomedcentral.com/submissions 